\title{
Inter- and intraindividual variation in pressure- volume relations of the rectum in normal subjects and patients with the irritable bowel syndrome
}

\author{
G P N Kendall, D G Thompson, S J Day, J E Lennard-Jones
}

\begin{abstract}
The relation between intrarectal volume and pressure during increasing rectal distension by a latex balloon were studied on repeated occasions in 10 healthy adult volunteers to define variations within and between individuals. A wide intersubject variation in the maximum tolerable volume $(58-908 \mathrm{ml})$ and pressure $\left(12 \cdot 2-108.8 \mathrm{~cm} \mathrm{H}_{2} \mathrm{O}\right)$ at this end point was seen, and these two values were correlated $(\mathrm{r}=\mathbf{0 . 7 8 )}$. Intrasubject variation in maximum tolerable volume also occurred which was related to study order and progressively reduced with repeated study. In 26 unselected patients with pain predominant irritable bowel syndrome similar intersubject variation was noted and virtually all patient data fell within the calculated $95 \%$ confidence limits of the normal individuals. Differentiation between patients and normal subjects was not possible from knowledge of rectal responses. These noticeable inter- and intrasubject variations in rectal responses to distension need to be considered whenever similar techniques are proposed for use in the study of rectal disease or of rectal response to treatment.
\end{abstract}

Studies of the relation between intraluminal pressure and volume of the rectum have been performed for the past 40 years since White et al ${ }^{1}$ modified the technique of cystometrography ${ }^{2}$ for the investigation of neurological conditions affecting the colon. Using similar methods, differences have been reported to exist between normal subjects and groups of patients with a variety of colonic disorders including constipation, ${ }^{3}$ the irritable bowel syndrome, ${ }^{4}$ and radiation proctitis. ${ }^{5}$ Modifications of the technique have also been used to study the effect of drugs on rectal function ${ }^{6}$ and to define a rheological model of the rectum in response to stretch. ${ }^{7}$ Despite this continued clinical interest, however, information on the responses of the normal rectum to distension is scanty and the reproducibility of the technique in healthy subjects has never been assessed in sufficient detail for a normal range of data to be constructed with any confidence.

We therefore performed a series of repeated studies on healthy subjects to define the reproducibility of some currently used techniques and to construct a normal range of response. We then compared these data with those subsequently obtained from patients with the irritable bowel syndrome to test the assertion ${ }^{49}$ that an abnormal response to rectal distension can be shown in this condition.
Method

\section{SUBJECT SELECTION}

The protocols for the studies performed were approved by the local district ethics committees and all participants gave their informed consent before the study.

Ten healthy adults (eight men and two women aged 18-21 years) with no previous history of gastrointestinal disorder were studied. Twenty six patients (Table I) suffering from the irritable bowel syndrome underwent similar examination. The diagnosis was made from an appropriate history ${ }^{1011}$ and was supported by a normal physical examination, sigmoidoscopy, full blood count, erythrocyte sedimentation rate, biochemical profile, and barium enema.

\section{PREPARATION FOR STUDY}

All subjects and patients were requested to defecate immediately before the study and digital examination of the rectum was always performed before insertion of the manometry assembly to check that the rectum was clear of faeces.

\section{APPARATUS}

Rectal distension was performed using a previously developed technique. ${ }^{3}$ A highly compliant balloon, constructed from a $7 \mathrm{~cm}$ length of condom, was tied round a central polyvinyl chloride inflation tube (internal diameter $4.3 \mathrm{~mm}$ ). Intraballoon pressures were measured via an open ended polyvinylchloride capillary tube (internal diameter $0.63 \mathrm{~mm}$, external diameter $1.4 \mathrm{~mm}$ ) perfused at $0.4 \mathrm{ml}$ minute by a pneumohydraulic pump. " Pressure changes, transmitted to the proximal end of the capillary tube, were detected by an attached strain gauge transducer (Gaeltec, Sb8, Skye, Scotland), the output of which was displayed on a chart recorder (Watanabe Linear Corder Mark VII, Tokyo, Japan) operating at a speed of 25 $\mathrm{mm} /$ minute.

The balloon was distended with water, at $37^{\circ} \mathrm{C}$, using a peristaltic pump (Watson-Marlow $502 \mathrm{~s}$, Falmouth, Cornwall), which infused the water at a predetermined rate independent of intraballoon pressure, the volumes infused being determined by the duration of the perfusion.

Before each study the balloon was distended on the bench to enable its intrinsic pressurevolume characteristics to be identified. Intrarectal pressures were then calculated as in previous experiments by subtracting these balloon pressures from those recorded during the study. 
Figure 1: (A) The six pressure-volume tracings obtained from two subjects (4 and 7) on day 1 are shown to give an indication of the similarity of the responses within an individual even though the character of the response between individuals ranged widely.

The dotted line represents the pressure/volume profile of the balloon when inflated in air.

$(B)$ This figure shows the six pressure-volume curves per day from studies performed on days 1,2 , and 3 on two subjects (4 and 7). The individuality of the pattern of rectal response to distension is evident on each occasion in each individual despite variations in the maximal tolerated volume.
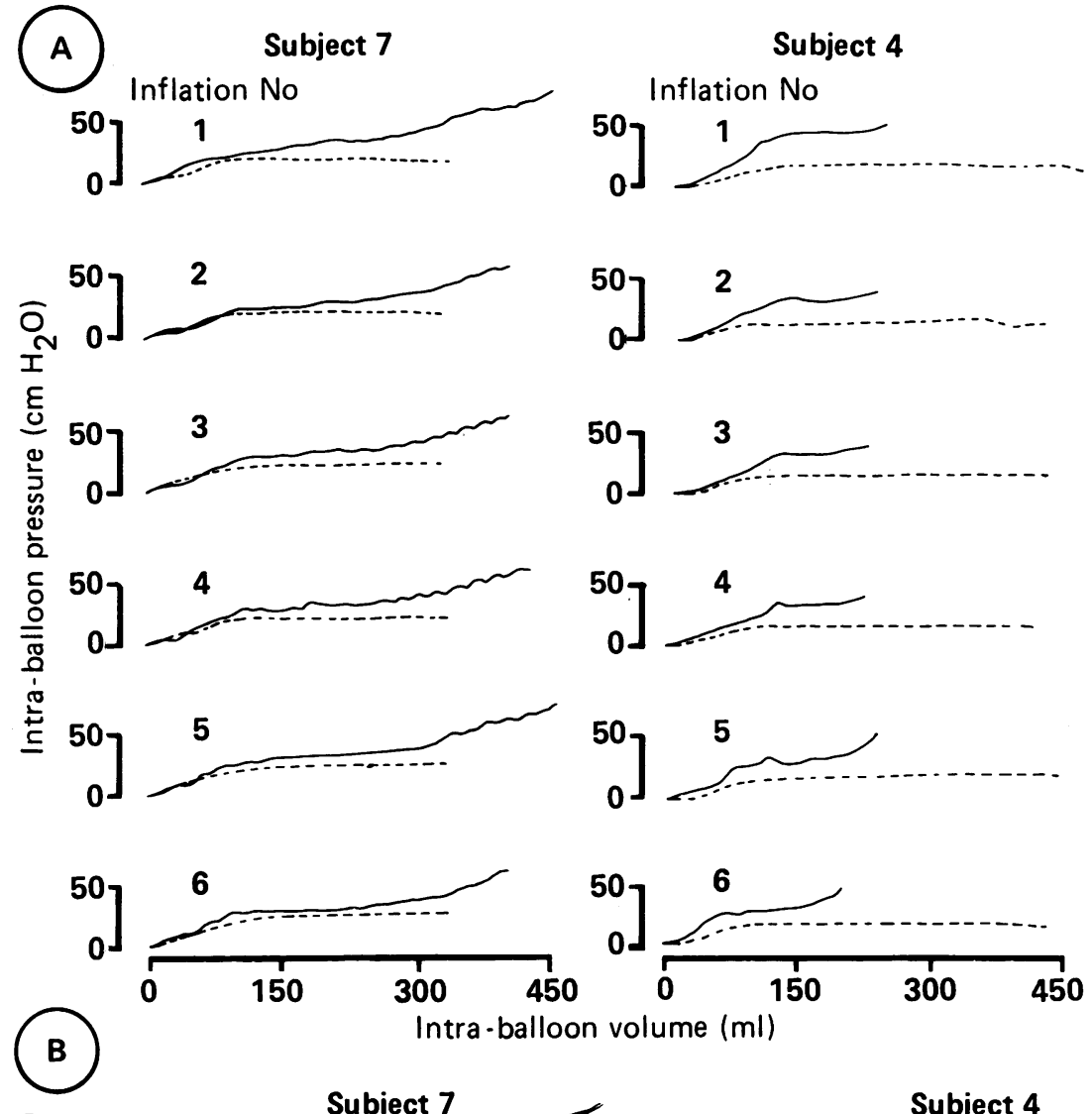

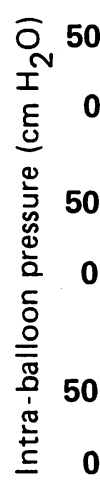

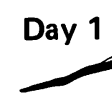

Subject 7
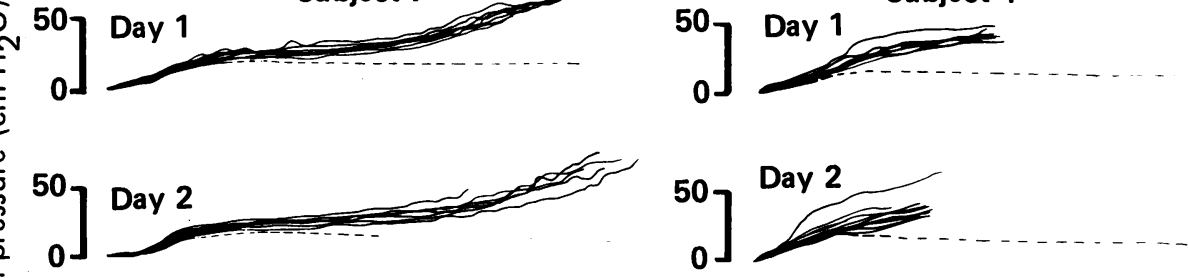

Subject 4

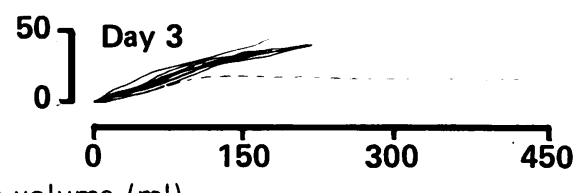

\section{EXPERIMENTAL PROTOCOLS}

\section{Normal subjects}

After an overnight fast the subjects reclined on an examination couch in left lateral position and the balloon assembly was introduced into the rectum. On each study day each subject underwent six rectal distensions with a five minute period between each inflation. This procedure was repeated on at least three days (maximum six days) at an inflation rate of $150 \mathrm{ml} /$ minute in all subjects. In five of the subjects additional studies were then performed at rates of $70 \mathrm{ml} /$ minute and $240 \mathrm{ml} / \mathrm{minute}$ (three studies at each rate), the order of these additional studies being randomised.

The sensory end points identified by the subjects were those previously defined. ${ }^{3-589}$ During each inflation the subjects were first asked to indicate the onset of awareness of the sensation of distension induced by the balloon and then, as inflation continued, to say when the distension had reached the limit of tolerance. They were also asked to describe the quality of the sensation at each sensory end point and to compare these sensations with those experienced at previous inflations.

\section{Patient studies}

The patients were studied in a similar manner on one day only using an inflation rate of 150 $\mathrm{ml} /$ minute. In addition to reporting the two sensory end points they were also asked to state whether these sensations resembled the pain they usually experienced.

\section{INTERPRETATION OF THE DATA}

\section{Normal subjects}

For each subject a series of pressure-volume curves was obtained (Fig 1) from which the maximum tolerable volume and pressure were 
Figure 2: The pressurevolume relations at the limit of tolerance for the 295 inflations performed in the normal subjects. The line surrounding the points represents the $95 \%$ bivariate confidence region for this relation.

Figure 3: The relation between volume and pressure for data collected on the first study day in the 10 individuals, together with the $95 \%$ bivariate confidence region for this relation.

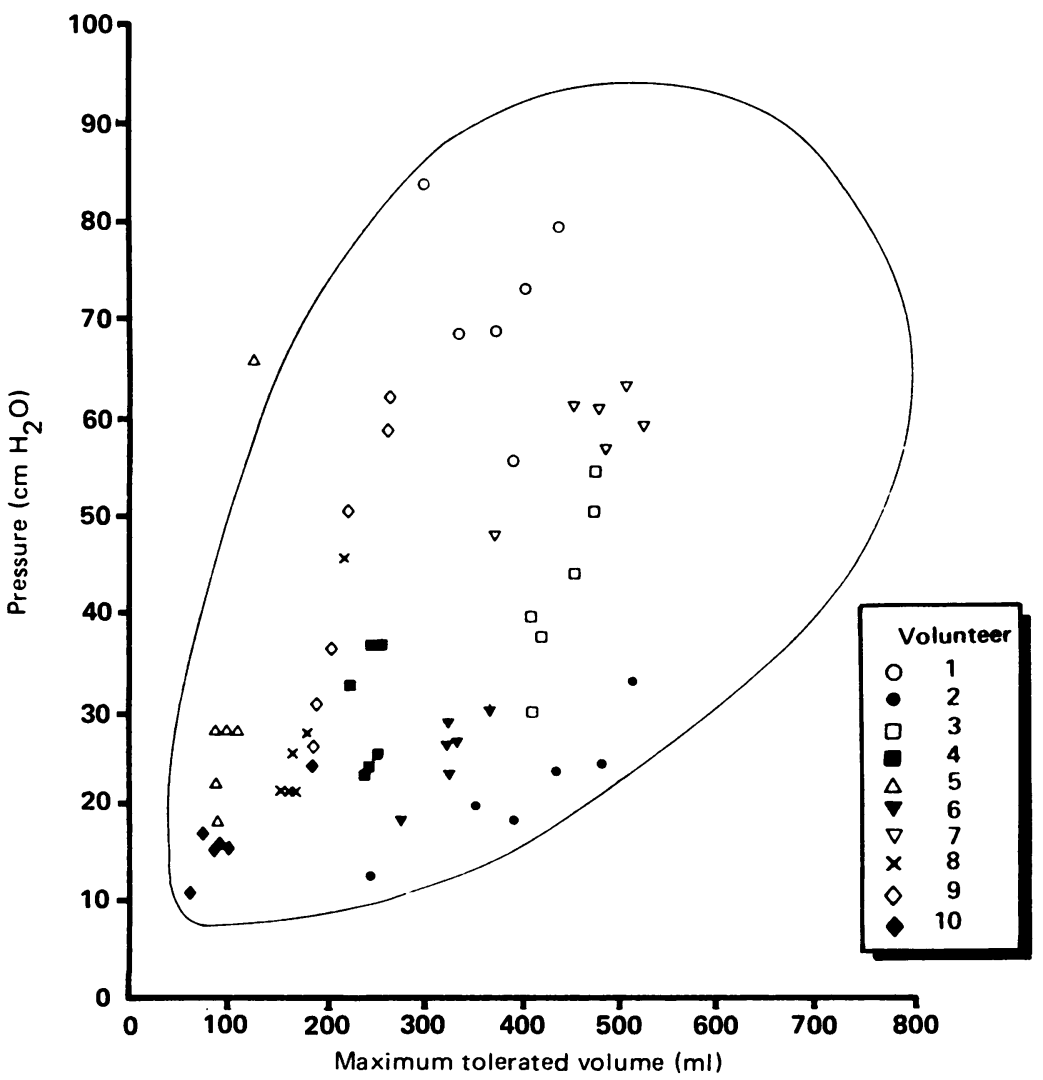

tolerable volume and pressure was studied correlation coefficients ${ }^{13}$ and a normal range for this relation (the $95 \%$ bivariate confidence region) was calculated using Hotelling's $\mathrm{T}^{2}$ distribution. ${ }^{1+}$ In outline, this method will include the mean (2 SD) for both pressure and volume but will exclude extreme values of pressure and volume - that is, high pressure and low volume, low pressure and high volume. The extent to which these clinically untenable pressurevolume possibilities are excluded is determined by the correlation between pressure and volume. Because the confidence region so determined is only correct for a bivariate normal distribution and because inspection of the raw data showed them to be positively skewed in distribution, a cube root transformation was applied to the data before analysis to render them more normal. The graphs (Figs 2 and 3) showing the results of these analyses, however, were made using retransformed values.

Since rectal wall tension is dependent upon the circumference of the rectum and hence that of the distending balloon, and since the circumference of the cylindrical balloon is largely proportional to the square root of its volume, ${ }^{15}$ the square root of the volume was used to compare data obtained on different occasions in the same subject. Because the maximum tolerable volumes varied greatly between subjects, differences between successive distending volumes for each person were calculated as ratios. For the analysis of variation between maximum tolerable volumes for an individual on the same day, comparisons were made between the value obtained at the first distension and the mean of the subsequent five, this method being chosen to avoid extreme results. For comparison of data obtained on different days, the mean of all the inflations on the first day was compared with similar data from the subsequent days of study.

\section{Results}

\section{NORMAL SUBJECTS}

\section{Rectal sensation during distension}

In the $150 \mathrm{ml} /$ minute experiments, all subjects described rectal distension in similar terms. Threshold sensation was described as something present in the rectum and maximum tolerable volume as an intense and urgent desire to evacuate the bowels. They also stated that these sensations were similar when the inflations were compared with each other both on the same and on different days. At the faster and slower inflation rates, however, the quality of the sensation seemed to differ, having a duller nature at the slower speed and a sharper quality at the more rapid rate.

\section{Results for the $150 \mathrm{ml} / \mathrm{minute}$ inflation studies}

Pressure-volume profile. The shapes of the pressure-volume curves varied between subjects (Fig 1(A) and (B)), but successive curves were similar in pattern for individuals despite variation in the maximum tolerable volume. Thus rectal responses for an individual seemed to remain relatively constant although perception of maximal tolerance varied.

Intersubject variation. Wide intersubject variation in both the maximum tolerable volume (range 58-908 $\mathrm{ml}$ ) and pressure at this end point (range $12 \cdot 2-108 \cdot 8 \mathrm{~cm} \mathrm{H} \mathrm{H}_{2} \mathrm{O}$ ) was seen, although as might be expected, the two correlated closely $(r=0 \cdot 78,95 \%$ confidence limits $0 \cdot 73-0 \cdot 83$ ). To give a better indication of this variation, the normal range for this relation $(95 \%$ bivariate confidence region) for all the studies is shown in Figure 2. A similar demonstration of data collected from the first study day only is shown in Figure 3 to allow comparison with the patient data 
Figure 4: The variation in the tolerated volume of successive inflations on days 1 and 3 is shown as a percentage of the value for the first inflation on each day. Each line joins the values for an individual subject.

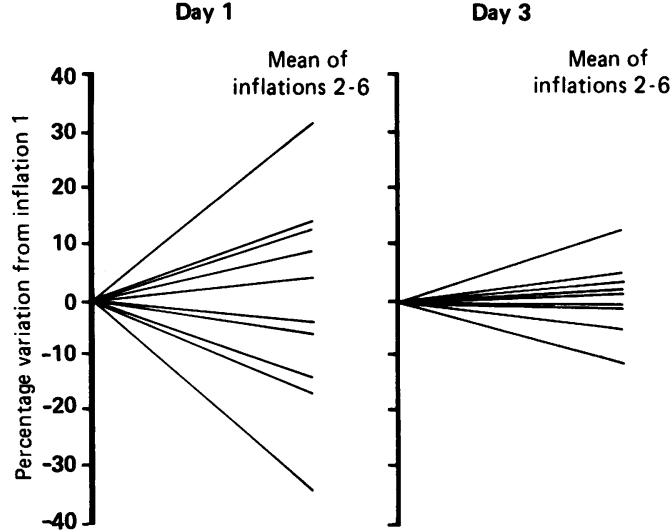

Intrasubject variation. In addition to the large intersubject variation, an appreciable variation in maximum tolerable volume was seen within each subject. This variation was greatest on the first day of study, the ratio of the difference between the first inflation and mean of the second to sixth inflations ranging between 66 $131 \%$. The variation lessened with the study day until the third and subsequent days (range 90 $117 \%$ ). Some subjects showed a progressive rise in maximum tolerable volume for a given study day while in others it fell (Fig 4). In all subjects, however, there was a progressive increase in the overall maximum tolerable volume for each day as the study progressed (Fig 5) until the fourth study day, after which it remained stable.

\section{Results for the $70 \mathrm{ml} /$ minute and $240 \mathrm{ml} / \mathrm{minute}$ studies}

These results are shown in Figure 6 together with the $150 \mathrm{ml} /$ minute studies in those five individuals who performed all the studies. For sake of clarity only data for days 1 and 3 are shown. It is apparent that maximum tolerated volumes did not vary in any consistent manner at the different speeds. Using analysis of variance, there was again no convincing evidence of differences in maximum tolerated volumes between different inflation speeds $(F=3.38$ with 2 and 8 degrees of freedom, $p=0.09$ ).

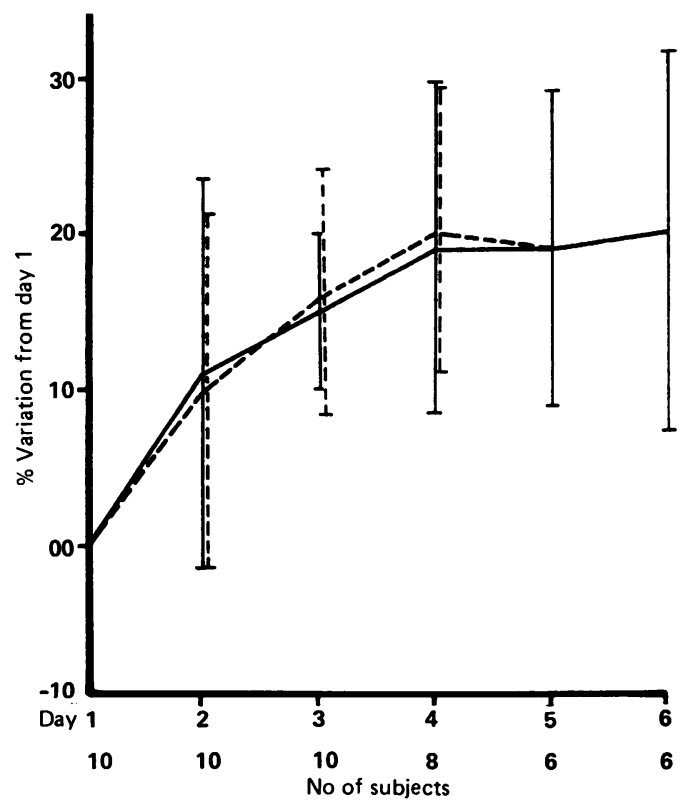

PATIENT STUDY DATA

Individual patient data together with the experimental results are shown in Tables I and II.

A wide interindividual range in maximum tolerable volume (range $43-396 \mathrm{ml}$ ) and pressure at this volume (range $9.0-57.9 \mathrm{~cm} \mathrm{H} \mathrm{H}_{2} \mathrm{O}$ ) was seen, which was of a similar magnitude to that recorded from the normal subjects. Comparison of the patient data with those obtained from the normal subjects (Fig 7) showed that only five of the 87 patient data points lay outside the normal $95 \%$ confidence limits irrespective of the age or sex, although they did tend to cluster at the lower end of the range.

\section{Sensation reported}

Sixteen patients noted that distension of the rectum reproduced their previously noted pain in site, character, and radiation. Although most patients felt pain in the left iliac fossa, nine found that rectal distension caused pain elsewhere in the abdomen. Six of these patients also found that rectal distension caused pain at extraabdominal sites, five noting pain radiating down the legs and one noting pain in the lumbar area.

\section{Discussion}

Our studies show that while the overall pressurevolume responses of the normal rectum to distension are reasonably consistent for a given individual, there is a noticeable variation in end point perception, with widely differing maximum tolerable volumes both within and between individuals. The shapes of the pressure-volume curves in response to distension also seem to vary considerably between people; some tolerate only small volumes before a rise in pressure occurs, while others tolerate large volumes.

A major component of the intrasubject variation in maximum tolerable volume seems to be order of study. Maximum tolerable volumes increase overall with repeated study even though for an individual, the volume tolerated may lessen during a single study day. This observation taken together with a relatively consistent pressure-volume pattern for each individual suggests that the changes are most probably due to alterations in end point perception rather than changes in rectal physiology. Such subjective end points therefore give a misleading impression of variation in response to distension.

In an attempt to remove the difficulties introduced by such subjectivity, some authors ${ }^{416}$ have attempted to derive compliance measurements from the pressure-volume traces. Our attempts to make similar measurements using their method, however, were unsuccessful since, as can be seen from the raw figures, for any curve several widely different values for its slope could be obtained, depending upon the point on the curve at which it is taken. These different values probably relate to the different components of the pressure-volume response of the rectum to distension recognised by Arhan et al in their rheological model and indicate that a single value of compliance probably does not exist. Unfortunately, therefore, despite the similarity of successive curves for any given individual, there 
Subject

$70 \mathrm{ml} / \mathrm{min}$

No

4

3

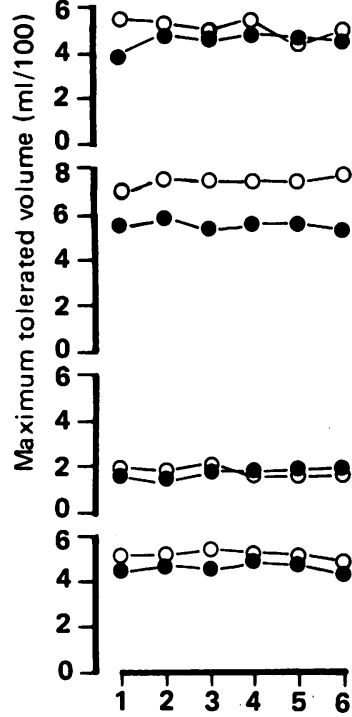

$150 \mathrm{ml} / \mathrm{min}$
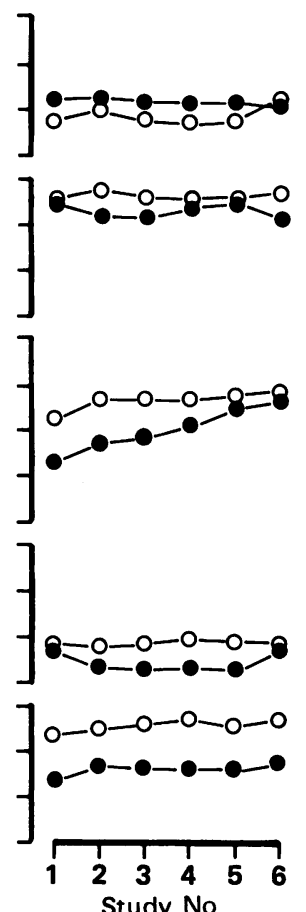

$240 \mathrm{ml} / \mathrm{min}$
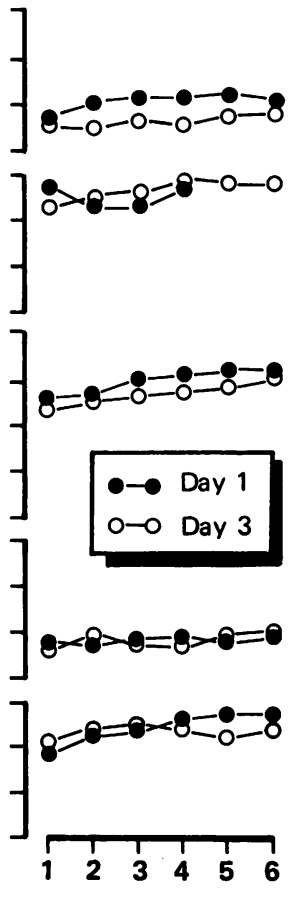

Figure 6: Maximum tolerated volumes for the five subjects who completed the studies at the three different inflation speeds. Study numbers indicate the six inflations on each study day.

TABLE I Patient details

\begin{tabular}{|c|c|c|c|c|c|}
\hline \multirow[b]{2}{*}{$\begin{array}{l}\text { Case } \\
\text { no }\end{array}$} & \multirow[b]{2}{*}{ Age } & \multirow[b]{2}{*}{ Sex } & \multirow[b]{2}{*}{ History } & \multicolumn{2}{|c|}{ Rectal inflation range } \\
\hline & & & & $\underset{(m l)}{M T V}$ & $\begin{array}{l}\mathrm{MTP} \\
\left(\mathrm{cm} \mathrm{H}_{2} \mathrm{O}\right)\end{array}$ \\
\hline 1 & 34 & $\mathbf{F}$ & $\begin{array}{l}2 \text { years LIF pain radiating to shoulder, constipation, } \\
\text { prior hysterectomy and cystectomy for irritable } \\
\text { bladder }\end{array}$ & $264-327$ & $36 \cdot 2-48 \cdot 2$ \\
\hline 2 & 24 & $\mathbf{F}$ & $\begin{array}{l}11 \text { year LIF pain going to back, distension, severe } \\
\text { constipation }\end{array}$ & $239-264$ & $10 \cdot 1-10 \cdot 7$ \\
\hline 3 & 31 & $\mathbf{F}$ & $\begin{array}{l}4 \text { year LIF and RIF pain going to legs, distension. } \\
\text { Normal bowel habit, prior hysterectomy }\end{array}$ & $119-131$ & $20-25$ \\
\hline 4 & 48 & $\mathbf{F}$ & $\begin{array}{l}6 \text { year epigatric and LIF pain going down legs, } \\
\text { distension, bowel frequency, prior hysterectomy, } \\
\text { depression }\end{array}$ & $57-66$ & $24-42$ \\
\hline 5 & 47 & F & $\begin{array}{l}1 \text { year LIF pain going to back and right shoulder, } \\
\text { constipation, prior laparoscopic sterilisation }\end{array}$ & $126-162$ & $13 \cdot 8-16 \cdot 1$ \\
\hline $\begin{array}{l}6 \\
7\end{array}$ & $\begin{array}{l}47 \\
46\end{array}$ & $\begin{array}{l}M \\
F\end{array}$ & $\begin{array}{l}5 \text { year episodic LIF pain, normal bowel habit } \\
5 \text { year } R \text { sided and suprapubic pain, constipation, } \\
\text { prior hysterectomy }\end{array}$ & $\begin{array}{l}291-296 \\
101-265\end{array}$ & $\begin{array}{l}48 \cdot 9-53 \cdot 2 \\
22 \cdot 9-31 \cdot 2\end{array}$ \\
\hline 8 & 40 & $\mathbf{F}$ & $\begin{array}{l}12 \text { year LIF pain, distension, constipation, agitated } \\
\text { depression, alcoholism }\end{array}$ & $65-138$ & $24-51 \cdot 2$ \\
\hline 9 & 27 & $\mathbf{F}$ & $\begin{array}{l}3 \text { years lower abdominal pain, distension, } \\
\text { constipation, prior caesarean section }\end{array}$ & $79-112$ & $12-27 \cdot 9$ \\
\hline 10 & 36 & $\mathbf{F}$ & $\begin{array}{l}1 \text { year } \mathrm{R}+\mathrm{L} \text { sided abdominal pain, alternating } \\
\text { diarrhoea and constipation }\end{array}$ & $107-396$ & $19 \cdot 2-42 \cdot 2$ \\
\hline $\begin{array}{l}11 \\
12 \\
13 \\
14\end{array}$ & $\begin{array}{l}46 \\
33 \\
44 \\
35\end{array}$ & $\begin{array}{l}\mathrm{F} \\
\mathrm{F} \\
\mathrm{M} \\
\mathrm{F}\end{array}$ & $\begin{array}{l}1 \text { year RIF pain, distension, constipation } \\
13 \text { year LIF and RIF pain, constipation } \\
2 \text { year RIF and RUQ pain } \\
3 \text { year lower abdominal pain, alternating constipation } \\
\text { and diarrhoea }\end{array}$ & $\begin{array}{r}196-224 \\
99-147 \\
161-246 \\
43-73\end{array}$ & $\begin{array}{l}9-13 \\
28 \cdot 4-57 \cdot 6 \\
28 \cdot 6-46 \cdot 4 \\
9-16 \cdot 7\end{array}$ \\
\hline $\begin{array}{l}15 \\
16 \\
17 \\
18\end{array}$ & $\begin{array}{l}72 \\
62 \\
58 \\
26\end{array}$ & $\begin{array}{l}\mathrm{F} \\
\mathrm{F} \\
\mathrm{M} \\
\mathrm{F}\end{array}$ & $\begin{array}{l}4 \text { year lower abdominal pain, bloating, constipation } \\
7 \text { year RIF pain, constipation } \\
1 \text { year LIF pain, normal bowel habit } \\
3 \text { year RIF pain, distension, alternating constipation } \\
\text { and diarrhoea }\end{array}$ & $\begin{array}{l}196-326 \\
115-229 \\
101-178 \\
138-192\end{array}$ & $\begin{array}{l}20 \cdot 8-55 \\
9 \cdot 7-33 \cdot 9 \\
17 \cdot 2-34 \cdot 8 \\
10-15 \cdot 8\end{array}$ \\
\hline 19 & 68 & F & 5 years lower abdominal pain, constipation, anxiety & $105-111$ & $18 \cdot 7-21 \cdot 9$ \\
\hline 20 & 54 & $\mathbf{F}$ & $\begin{array}{l}3 \text { year LIF and epigastric pain, constipation, prior } \\
\text { hysterectomy }\end{array}$ & $73-80$ & $21 \cdot 1-30 \cdot 2$ \\
\hline 21 & 48 & $\mathbf{F}$ & $\begin{array}{l}5 \text { year LIF pain, alternating constipation and } \\
\text { diarrhoea, prior hysterectomy }\end{array}$ & $241-268$ & $21 \cdot 8-47 \cdot 8$ \\
\hline 22 & 57 & $\mathrm{~F}$ & $\begin{array}{l}5 \text { years lower abdominal pain going to LUQ and } L I F \text {, } \\
\text { constipation }\end{array}$ & $116-190$ & $10 \cdot 5-12 \cdot 5$ \\
\hline $\begin{array}{l}23 \\
24 \\
25\end{array}$ & $\begin{array}{l}63 \\
35 \\
56\end{array}$ & $\begin{array}{l}\mathrm{F} \\
M \\
\mathrm{~F}\end{array}$ & $\begin{array}{l}2 \text { year anal pain going to back and legs } \\
2 \text { year LIF and LUQ pain, diarrhoea } \\
2 \text { year LIF and pelvic pain, alternating constipation } \\
\text { and diarrhoea }\end{array}$ & $\begin{array}{c}103-138 \\
47-56 \\
100-149\end{array}$ & $\begin{array}{l}43 \cdot 4-57 \cdot 9 \\
17 \cdot 3-21 \cdot 8 \\
21 \cdot 1-38 \cdot 3\end{array}$ \\
\hline 26 & 37 & $M$ & 10 year RIF pain & $126-162$ & $11 \cdot 7-25$ \\
\hline
\end{tabular}

$M T V=$ maximum tolerated volume; $M T P=$ maximum tolerated pressure; $L I F=$ left iliac fossa; $\mathrm{RIF}=$ right iliac fossa; $R U Q=$ right upper quadrant; $L U Q=$ left upper quadrant.

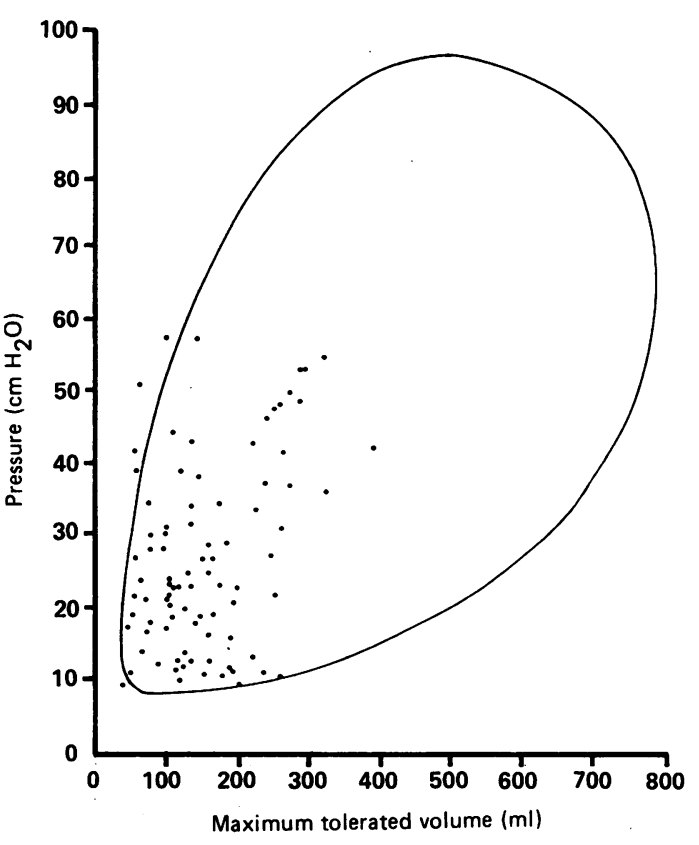

Figure 7: The relation between the maximum tolerable volume and pressure for the patient data is shown. The $95 \%$ bivariate confidence region from Figure 3 is shown to allow comparison with the normal subjects.

does not yet seem to be a suitable mathematical method capable of describing the various patterns, and pressure-volume descriptions still await objective analysis.

Previous studies of patients with the irritable bowel syndrome $\mathrm{e}^{3489}$ have described differences between groups of patients and matched controls, but the diagnostic importance of these group differences for individual patients has been difficult to determine. Our results suggest that the diagnostic value of the technique is poor since virtually all our patients showed responses which fell within our wide range of normality. Although there was a tendency for the patient data to cluster at its lower end, it is difficult to know whether this represents a true difference in rectal physiology or indicates reduced tolerance to the discomfort of distension. Physiological differences seem unlikely, however, in view of the normal appearance of the pressure-volume curves in most patients.

Our results for repeated studies at different rates show that over the inflation rates chosen no obvious differences in normal rectal performance could be detected. This situation may not of course persist in irritable bowel syndrome patients, in whom we were unable to obtain data for different inflation speeds. Previous reports, ${ }^{17}$ for example, indicate that large volumes rapidly infused in patients with irritable bowel syndrome and normal controls produced indistinguishable responses. When smaller volumes were infused more slowly, however, the two groups could be distinguished in terms of contractile activity induced. Further studies at a range of inflation speeds below those which we employed seem justified to explore this possibility in greater detail.

In considering the patient data further, it must be emphasised they were not strictly comparable in terms of sex and age with those of the normal subjects. However, our failure to show any 
TABLE II Relation between age and sex of patient $\mathrm{v}$ maximum tolerable volume

\begin{tabular}{lccclll}
\hline $\begin{array}{l}\text { Age of } \\
\text { patient }\end{array}$ & $\begin{array}{l}\text { No of } \\
\text { patients }\end{array}$ & $\begin{array}{l}\text { No of } \\
\text { readings }\end{array}$ & $\begin{array}{l}\text { Range } \\
(\boldsymbol{m l})\end{array}$ & $\begin{array}{l}\text { Median } \\
(\boldsymbol{m l})\end{array}$ & $\begin{array}{l}\text { Mean } \\
(\boldsymbol{m l})\end{array}$ & $\begin{array}{l}95 \% C L \\
(\boldsymbol{m l})\end{array}$ \\
\hline $20-29$ & 3 & 8 & $79-264$ & 159 & $162 \cdot 5$ & $114 \cdot 5-210 \cdot 5$ \\
$30-34$ & 3 & 9 & $99-327$ & 131 & 179 & $122-236$ \\
$35-39$ & 4 & 18 & $43-396$ & $131 \cdot 5$ & $128 \cdot 3$ & $88-168$ \\
$40-44$ & 2 & 7 & $65-246$ & 138 & 145 & $118-199$ \\
$45-49$ & 6 & 20 & $57-296$ & $214 \cdot 5$ & 194 & $156-232$ \\
$50-59$ & 4 & 14 & $73-190$ & 111 & 123 & $103-143$ \\
$60+$ & 4 & 11 & $103-326$ & 120 & 167 & $119-215$ \\
Female & 21 & 72 & $43-396$ & 137 & 155 & $137-173$ \\
Male & 5 & 15 & $47-296$ & 161 & 169 & $125-213$ \\
\hline
\end{tabular}

consistent differences between maximal tolerated volumes in the patients and the normal subjects must indicate that real differences are unlikely, since studies controlling for these factors would be expected to reduce rather than increase differences between test and control data.

It must also be accepted that our patient group, like all other groups of patients with functional bowel disease, was rather heterogeneous in terms of symptomatology. Comparison of the data in Table I and Figure 8, however, fails to indicate any consistent relation between symptom type and the rectal response.

Our results seem initially to be quite different from those reported recently by Varma and Smith, ${ }^{16}$ who concluded that the method was highly reproducible and reliable for use in clinical practice and research. In their study, 15 patients with a variety of diseases were each

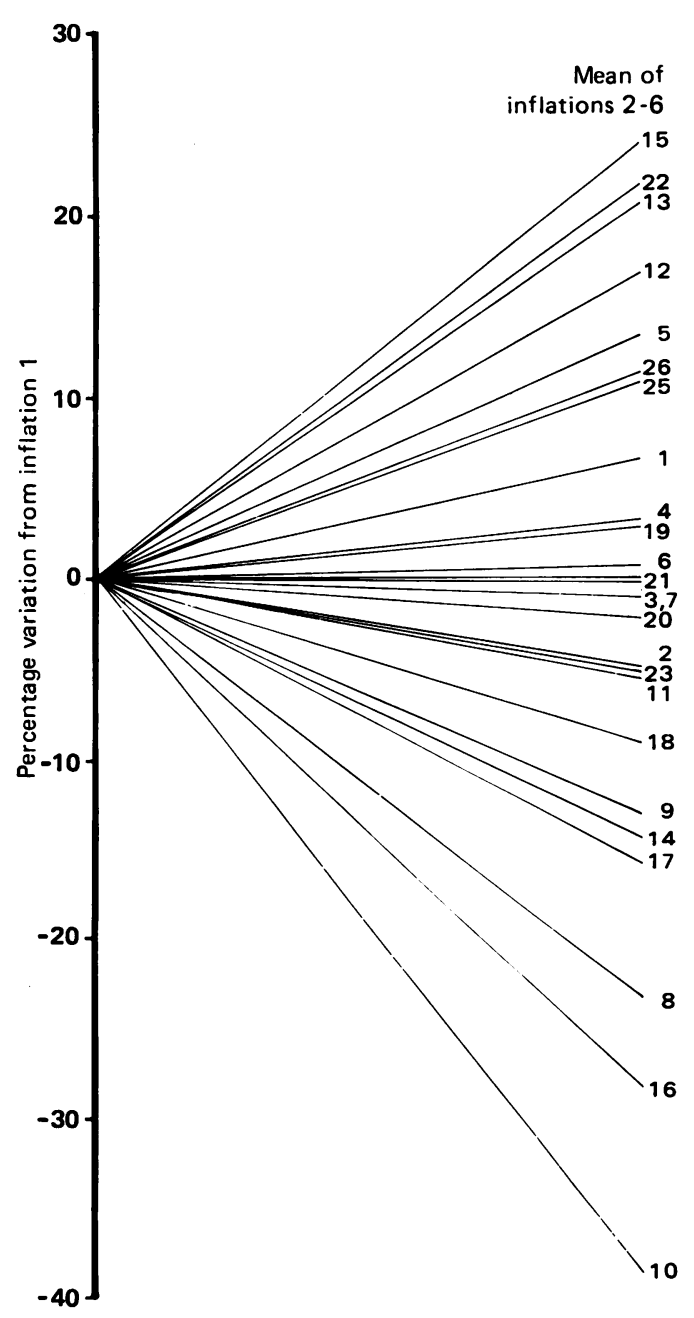

evaluated twice using a similar inflation technique at a rate of inflation of $67 \mathrm{ml} /$ minute. In seeking to explain these differences a number of possibilities arise. Firstly, the greater number of individuals recruited and the greater repetition in our study would naturally favour detection of a wider range. Secondly, the selection of patients with rectal diseases such as radiation injury or megacolon may have inadvertently introduced bias in favour of reproducibility.

In addition to the question of reproducibility, the standard proctometrogram technique makes a number of theoretical assumptions which require critical discussion. For example, it is assumed that the balloon remains spherical and uniformly distends the rectal wall upon inflation. It seems likely, however, in practice that the balloon will increase its length as well as its diameter during distension as it does in air. For practical reasons, however, it is difficult to justify the exposure to $x$ rays in normal subjects in order to be certain of balloon conformity, so that it is possible that the volume of the balloon indicated not only the volume of the rectum but distal sigmoid too. What this study does indicate, however, is that the receptivity of the lower bowel in healthy volunteers is rather larger than previously believed.

These technical limitations together with the wide range of response both in patients and normal individuals make it difficult to envisage how the presently conducted proctometrogram could reliably detect abnormalities of rectal function except perhaps when the rectal disease is gross - for example, contraction due to radiation. ${ }^{5}$ In these patients, however, abnormalities of the rectum are usually readily identified by simpler investigation

The usefulness of the method for studying effects of drugs on rectal function is also brought into question by the wide range of normality. For example it can be predicted that at least 100 subjects would need to be recruited for a drug to show an alteration in rectal performance of $25 \%$, with $95 \%$ confidence.

Based on current information we therefore suggest that differences found using the proctometrogram between groups of normal subjects and patients should be interpreted with caution until more precise techniques become available.

Dr Kendall was supported by the British Digestive Foundation and Dr Thompson was a Wellcome Trust Senior Lecturer in Medicine.

The authors wish to acknowledge the secretarial help of Mrs J Young and Mrs J Hamilton.

1 White JC, Verlot MG, Ehrentheil O. Neurogenic disturbances of the colon and their investigation by the colonmetrogram Ann Surg 1940; 112: 1042-57

2 Rose DK. Determination of bladder pressure with the

systometer. fAMA 1927; 88: 151-7.
Preston DM, Barnes PRH, Lennard-Jones JE. Proctometrogram: does it have a role in the evaluation of adults with chronic constipation? Gut 1983;24:1010-1.

4 Varma JS, Smith AN. Abnormalities of rectal distensibility in the irritable bowel syndrome [Abstract]. Gut 1984; 25 : the irritable bowel syndrome [Abstract]. Gut 1984; 25: Al169.

Varma JS, Smith AN. Rectal function after pelvic irradiation Gut 1984; 25: 554.

6 Lipkin M, Almy T, Bell BM. Pressure-volume characteristics of the human colon. $\mathcal{F}$ Clin Invest 1962; 41: 1831-9.

7 Arhan P, Faverdin C, Persoz B, et al. Relationship between visco-elastic properties of the rectum and anal pressure in man. F Appl Physiol 1976; 41: 677-82.

8 Ritchie J. Pain from distension of the pelvic colon by inflating a balloon in the irritable bowel syndrome. Gut 1973; 14: 125 32 . 
9 Kullmann G, Fielding JF. Rectal distensibility in the irritable bowel syndrome. Irish Med F 1981; 74: 140-2.

10 Manning AP, Thompson WG, Heaton KW, Morris AF Towards a positive diagnosis of the irritable bowel. $\mathrm{BrMed}$ 1978; ii: 653-4.

11 Lennard-Jones JE. Functional gastrointestinal disorders. N Engl f Med 1983; 308: 431-5.

12 Arndorfer RC, Stef JJ, Dodds WJ, Linehan JH, Hogan WJ Improved infusion system for intraluminal esophageal manometry. Gastroenterology 1977; 73: 23-7.
13 Armitage P. Statistical methods in medical research. 1st ed. Oxford: Blackwell Scientific Publications, 1971

14 Chatfield $\mathrm{C}$, Collins AB. Introduction to multivariate analysis. 1st ed. London: Chapman and Hall, 1980

15 Hopkins A. Relation between pressure and volume in hollow viscera. Gut 1966; 7: 521-4

16 Varma JS, Smith AN. Reproducibility of the proctometroarma JS, Smith AN. Reproduc
gram. Gut 1986; 27: 288-92.

17 Mitra R, Churar C, Ragendra GR, Shuster M. Abnormal responses to rectal distension in irritable bowel syndrome. Gastroenterology 1974; 66: A770. 